\title{
Risk factors for in-hospital death in acute ST-segment elevation myocardial infarction after emergency percutaneous coronary intervention: a multicenter retrospective study
}

\author{
Nan Gao ${ }^{1,2}$, Xiao-Yong $\mathbf{Q i}^{1,3}$ \\ ${ }^{1}$ School of Graduate, Hebei Medical University, Shijiazhuang, China; ${ }^{2}$ Department of Cardiology, Baoding No. 1 Central Hospital, Baoding, China; \\ ${ }^{3}$ Department of Cardiology, Hebei General Hospital, Shijiazhuang, China \\ Contributions: (I) Conception and design: XY Qi; (II) Administrative support: None; (III) Provision of study materials or patients: None; (IV) \\ Collection and assembly of data: N Gao; (V) Data analysis and interpretation: N Gao; (VI) Manuscript writing: Both authors; (VII) Final approval of \\ manuscript: Both authors. \\ Correspondence to: Xiao-Yong Qi, MD. Hebei Medical University, No. 361 Zhongshan East Street, Changan District, Shijiazhuang 050000, China. \\ Email: Qixiaoyong123@126.com.
}

\begin{abstract}
Backgroundh For some acute ST-segment elevation myocardial infarction (STEMI) cases, the risk of inhospital death remains high even after emergency percutaneous coronary intervention (PCI). This study sought to identify predictors of in-hospital mortality in STEMI patients after PCI.

Methods: Patients with acute STEMI, who underwent emergency PCI at Hebei General Hospital, Baoding First Central Hospital, and Cangzhou Central Hospital, from January 2016 to December 2018, were retrospectively included in this study. The patients' general data, previous medical history, clinical data and medication data were collected and compared between the survival and mortality groups. The primary outcome was in-hospital mortality. In-hospital mortality was defined as all-cause death during admission.

Results: Of the 1,169 patients (876 male and 293 female) enrolled in this study, 95 (8.13\%) died during hospitalization. The multivariate logistic regression analysis showed that being female [odds ratio (OR) $=5.86,95 \%$ confidence interval (CI): 2.03-16.92, $\mathrm{P}=0.001$ ], a Killip class of 2 (OR =8.13, 95\% CI: 2.03-32.61, $\mathrm{P}=0.003)$, a Killip class of 4 (OR $=17.31,95 \% \mathrm{CI}: 3.69-81.27, \mathrm{P}=0.001)$, a left main coronary artery lesion $(\mathrm{OR}=44.25,95 \%$ CI: 3.96-494.05, $\mathrm{P}=0.002)$, a final TIMI flow of 1 (OR =171.83, 95\% CI: 28.46-1037.51, $\mathrm{P}=0.001$ ), a final TIMI flow of 2 (OR =72.93, 95\% CI: 38.54-138.00, $\mathrm{P}=0.001$ ), symptom onset-to-door time (SDT) (OR =1.01, 95\% CI: 1.00-1.02, P=0.001), symptom onset-to-balloon dilatation time (SBT) (OR $=1.01$, 95\% CI: 1.00-1.02, P=0.001), and the Synergy Between PCI With Taxus and CABG (SYNTAX) score $(\mathrm{OR}=1.07,95 \% \mathrm{CI}$ : $1.01-1.12, \mathrm{P}=0.019)$ were risk factors; while postoperative $\beta$-receptor blockers (OR $=0.10,95 \% \mathrm{CI}: 0.03-0.30, \mathrm{P}=0.001)$ postoperative angiotensin-converting enzymes/angiotensin receptor blockers (OR $=0.13,95 \% \mathrm{CI}: 0.04-0.44, \mathrm{P}=0.001)$, BMI (OR =0.85, 95\% CI: $0.74-0.98, \mathrm{P}=0.024)$, the percentage of the ejection fraction $(\mathrm{OR}=0.81,95 \% \mathrm{CI}: 0.75-0.86, \mathrm{P}=0.001)$, and low-density lipoprotein cholesterol ( $\mathrm{OR}=0.44,95 \% \mathrm{CI}$ : $0.21-0.91, \mathrm{P}=0.027$ ) were protective factors for in-hospital mortality.

Conclusions: Female, Killip grade, a left main lesion, TIMI grade, SDT, SBT, and SYNTAX score were associated with a higher risk of in-hospital death. Conversely, BMI, ejection fraction, LDL-C level, and postoperative use of $\beta$-blocker and ACEI/ARB drugs were associated with a lower in-hospital death risk.
\end{abstract}

Keywords: Percutaneous coronary intervention (PCI); ST-segment elevation myocardial infarction (STEMI); hospital mortality; prognosis

Submitted Sep 14, 2021. Accepted for publication Oct 29, 2021.

doi: $10.21037 /$ apm-21-2722

View this article at: https://dx.doi.org/10.21037/apm-21-2722

(c) Annals of Palliative Medicine. All rights reserved. 


\section{Introduction}

Acute myocardial infarction (AMI) is the main cause of death in patients with cardiovascular diseases $(1,2)$. AMI consists of two types, that is, ST-segment elevation myocardial infarction (STEMI) and non ST-segment elevation myocardial infarction (NSTEMI). Nearly $40 \%$ of AMI cases arise from ST-segment elevation myocardial infarction (STEMI) (3), which results from the occlusion of 1 or more of the coronary arteries that supply the heart with blood.

Percutaneous coronary intervention (PCI) is the 1st-line treatment strategy for patients with acute STEMI, and PCI improves the prognosis of AMI patients (4-7). PCI reduces mortality in acute STEMI patients by about $22 \%$ compared to fibrinolysis (8); however, the mortality risk remains high for many patients in the hospital.

One factor that increases patient mortality is the noreflow phenomenon, which occurs when there is inadequate myocardial perfusion of the coronary artery without evidence of angiographic epicardial vessel obstruction, spasm, or dissection (9-11). Studies suggest that many factors may influence the risk of mortality after PCI, including age, Killip class, symptom onset to balloon time [based on a spontaneous breathing trial (SBT)], baseline thrombolysis in myocardial infarction (TIMI) flow, lesion length, reference vessel diameter, cutoff occlusion pattern, thrombus burden, SYNTAX score, mean platelet volume, platelet-lymphocyte ratio, increased creatinine, and elevated creatine kinase (4-7). During coronavirus disease 2019 (COVID-19) pandemic, a high GRACE score and COVID-19 were independent risk factors associated with higher in-hospital mortality for ST-segment elevation AMI and non-ST-segment elevation AMI (12). In relation to patient mortality, the question of whether these specific clinical features or others have predictive value in the prognosis of patients with acute STEMI after emergency PCI requires further investigation.

This study aimed to identify predictors of in-hospital mortality in STEMI patients after emergency PCI.

We present the following article in accordance with the STROBE reporting checklist (available at https://dx.doi. org/10.21037/apm-21-2722).

\section{Methods}

\section{Patients}

This study was a retrospective, multicenter, observational study. Patients with STEMI, who underwent emergency
PCI at Hebei General Hospital, Baoding No. 1 Central Hospital, and Cangzhou Central Hospital, from January 2016 to December 2018 were included in the study. To be eligible for inclusion in the study, patients had to meet the following inclusion criterion: have a diagnosis of acute STEMI with indications for PCI as per the current guidelines (13). Patients with acute STEMI who only underwent emergency coronary angiography but did not undergo coronary intervention were excluded from the study. All procedures performed in this study involving human participants were in accordance with the Declaration of Helsinki (as revised in 2013). The study was approved by institutional ethics research committee board of Baoding No. 1 Central Hospital (No. [2021]014). Individual consent for this retrospective analysis was waived.

\section{Emergency PCI procedures}

The procedures and protocols for emergency PCI were conducted according to the current guidelines (14). Patients with hemodynamic instability were treated with an intraaortic balloon pump (IABP) to increase the blood flow of the coronary artery and cerebral artery, and patients with pulmonary edema were treated with a non-invasive ventilator. All patients with acute STEMI were given 3,000 units of unfractionated heparin intravenously and $600 \mathrm{mg}$ of clopidogrel (Sanofi, Paris, France) before the procedure, followed by a long-term oral dose of $75 \mathrm{mg}$ of clopidogrel per day for at least 12 months, or $180 \mathrm{mg}$ of ticagrelor (AstraZeneca Pharmaceutical Co. Ltd, Sweden) followed by a maintenance dose of $90 \mathrm{mg}$ twice a day for at least 12 months. All patients were given $300 \mathrm{mg}$ of aspirin (Bayer Healthcare Co. Ltd, Germany) to chew before the procedure, and then received $100 \mathrm{mg}$ of aspirin per day.

\section{Data collection}

The collected patient data included data on age, gender, body mass index (BMI), history of smoking, history of alcohol consumption, family history of coronary heart disease, personal history of angina pectoris, hypertension, type 2 diabetes, myocardial infarction, cerebral infarction, chronic kidney disease, coronary intervention, atrial fibrillation and cerebral hemorrhage, heart rate, systolic blood pressure (SBP), diastolic blood pressure (DBP), Killip grade, blood results, including white blood cell count (WBC), red blood cell count, hemoglobin, platelet count, serum potassium, serum sodium, serum chlorine, serum 
creatinine, uric acid, cholesterol, triglyceride, low-density lipoprotein (LDL), high-density lipoprotein, random blood glucose, creatine kinase myocardial band (CK-MB) peak value, left ventricular ejection fraction (LVEF), chest pain at time from onset to first medical contact, time from onset to balloon dilatation, intervention information related to culprit blood vessels, lesion site, lesion diameter, lesion length, number of lesion blood vessels, the treatment of non-culprit blood vessels, collateral circulation, syntax score, thrombus score, thrombus aspiration, postoperative TIMI blood flow classification, IABP application, intraoperative slow blood flow, intraoperative ventricular fibrillation, central packing, $\beta$-blocker use, angiotensin-converting enzyme/angiotensin receptor blocker (ACEI/ARB) use, aldosterone use, diuretic use, and nicorandil use after admission. Commonly used drugs included angiotensinconverting enzyme inhibitors, statins, $\beta$-blockers, nitrates, and diuretics. For patients with AMI with a heavy intravascular thrombus load, a thrombus aspiration catheter was used to treat the thrombus (15).

A clinical evaluation was conducted after the first medical contact when the patient was admitted to hospital to determine each patient's Killip grade. Killip grade I was defined as AMI patients without clinical symptoms of heart failure; Killip grade II was defined as AMI complicated with left heart failure, and a wet rale of both lungs $<50 \%$ in the lung field; Killip grade III was defined as AMI with acute pulmonary edema, large, small, dry and wet rales of the whole lung; Killip grade IV was defined as hemodynamic changes of different degrees or stages such as AMI complicated with cardiogenic shock (16). Cardiogenic shock was defined as per the Kamir-NIH study; that is, as $>30 \mathrm{~min}$ of continuous SBP $<90 \mathrm{mmHg}$, and was characterized by terminal organ hypoperfusion (17).

Left ventricular function was evaluated by transthoracic echocardiography for the 1st time after STEMI was diagnosed. The patient was placed in a supine position for the echocardiography. As per the cutting-edge method of the American Society of Echocardiography, the internal dimensions of the left ventricle (i.e., end-systolic diameter and end-diastolic diameter) were measured using at least 3 consecutive cardiac cycles. LVEF was calculated as LVEF = (end-diastolic volume - end-systolic volume $) /$ end-diastolic volume. Left ventricular end-diastolic diameter and left ventricular end-systolic diameter were calculated using the Simpson method under 2-dimensional echocardiography (18).

The SYNTAX score, which is a scoring system based on the degree and scope of the coronary artery disease after coronary angiography, was used to assess cardiac disease grade (19).

The thrombus score was used to evaluate the degree of a thrombotic lesion. The thrombus score was assessed after the guidewire passed through the lesion (but before balloon dilation). The thrombus score was assigned using the following scale: 0 points if there was no thrombus under multiple, persistent cardiac cycles, and the intimal dissection caused by the guidewire in the false lumen was excluded; 1 point if there was a fuzzy thrombus shadow; 2 points if the length of the confirmed thrombus image was $<1 / 2$ of the inner diameter of the blood vessel; 3 points if there was a determined thrombus, the length of which was $1 / 2-2$ times greater than the inner diameter of the blood vessel; 4 points if there was a determined thrombus, the length of which was 2 times greater than the inner diameter of the blood vessel; and 5 points if blood vessel occlusion meant that the thrombus could not be evaluated (20).

TIMI was used for blood flow classification. TIMI blood flow classification was evaluated after coronary stent implantation and non-compliant balloon dilatation. TIMI grade 0 blood flow (no perfusion) was defined as no forward blood flow after coronary artery occlusion. TIMI grade 1 blood flow (no perfusion penetration) was defined as weak anterior coronary blood flow after occlusion, and the distal coronary bed not being completely filled. TIMI grade 2 blood flow (partial reperfusion) was defined as delayed or slow forward blood flow that completely filled the distal region. TIMI grade 3 blood flow (complete perfusion) referred to normal blood flow that completely filled the distal coronary bed (21).

\section{Observation outcome}

The primary outcome was in-hospital mortality. In-hospital mortality referred to all-cause death during admission.

\section{Statistical analysis}

All data were processed by SPSS 21.0 (IBM, Armonk, NY, USA). The independent sample $t$-, chi-square, and Mann-Whitney U-tests were used as applicable to assess variant differences between the mortality and survival groups. A single-sample Kolmogorov-Smirnov test was used for the normality test. Continuous variables of normal distribution are expressed by mean \pm standard deviation, while continuous variables of non-normal distribution are 


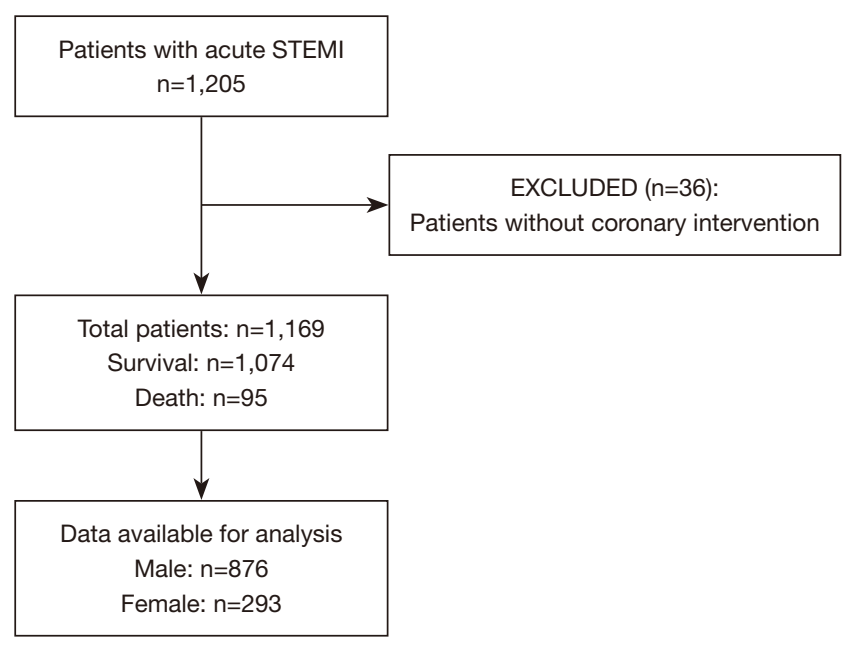

Figure 1 The flow diagram of the study.

expressed as median (interquartile range). The classification variable is represented by the $\mathrm{n}(\%)$. The missing data were replaced by the median. Univariable logistic regression analyses were used to screen out factors with a $\mathrm{P}$ value $<0.20$. The backward step-by-step iteration method was used for the multivariable binary logistic regression analysis to finally determine the risk factors related to hospital death. Odds ratios (ORs) were calculated with $95 \%$ confidence intervals (CIs). A P value $<0.05$ was considered statistically significant.

\section{Results}

\section{Baseline characteristics}

A total of 1,205 patients with acute STEMI met the inclusion criteria. Of these patients, 36 without coronary intervention, were excluded. Ultimately, 1,169 patients (876 male and 293 female) with acute STEMI, who underwent emergency PCI were included in this study as observation subjects. After the emergency PCI, a total of 1,074 patients survived during hospitalization, and 95 died during hospitalization (aged 59.6 \pm 11.4 years and $66.3 \pm 13.3$ years, respectively, $\mathrm{P}<0.001)$. Figure 1 shows a flow diagram of the study. The specific clinical features of all subjects are shown in Table 1.

Most patients survived after undergoing emergency PCI $(1,074 / 1,169,91.2 \%)$, but the proportion of females in the survival group was significantly lower than that in the mortality group $(24.0 \%$ vs. $36.8 \%, \mathrm{P}=0.006)$. Patients' mean SBP and DBP were higher in the survival group than the mortality group $(\mathrm{P}<0.001)$. Patients in the survival group were more likely to have a history of smoking $(48.2 \% \mathrm{vs}$. $36.8 \%, \mathrm{P}=0.033)$, but less likely to have a history of cerebral infarction $(14.3 \%$ vs. $22.1 \%, \mathrm{P}=0.042)$, and atrial fibrillation ( $1.6 \%$ vs. $5.3 \%, \mathrm{P}=0.011)$ than those in the mortality group. Patients' WBC was lower in the survival group than the mortality group $(10.64 \pm 3.38$ vs. $12.45 \pm 5.11, \mathrm{P}<0.001)$, and LDL cholesterol was higher in the survival group than the mortality group $(2.98 \pm 0.85$ vs. $2.67 \pm 0.70, \mathrm{P}<0.001)$.

At admission, fewer survival patients had a Killip class $\geq 2$ class $(\mathrm{P}<0.001)$, left main coronary artery $(\mathrm{P}<0.001)$, or left anterior descending coronary artery $(\mathrm{LAD}, \mathrm{P}=0.01$ ) infarction than mortality patients. Survival patients had more mid and distal culprit artery occlusion than mortality patients $(35.5 \%$ vs. $28.4 \%, 13.9 \%$ vs. $6.4 \%$, respectively, $\mathrm{P}<0.001)$, and their distribution of thrombus score fell between $0-3$ more often $(\mathrm{P}=0.005)$ than that of the mortality patients. LVEF, symptom onset-to-door time (SDT), SBT (i.e., the time of the crossing of the wire), and IABP application were lower in the survival group than the mortality group $(\mathrm{P}<0.001)$. After coronary angiography, the survival patients had lower SYNTAX scores than mortality patients $(20.71 \pm 7.67$ vs. $29.31 \pm 9.92, \mathrm{P}=0.003)$. A final TIMI flow of 3 was evident in more patients in the survival group than the mortality group $(94.4 \%$ vs. $60.0 \%, \mathrm{P}<0.001)$ after coronary stent implantation and non-compliant balloon dilatation. However, patients in the survival group were administered more $\beta$-blockers and ACEI/ARBs after admission $(\mathrm{P}<0.001)$ than those in the mortality group.

\section{Risk factors for in-hospital mortality after emergency PCI for patients with acute STEMI}

The risk factors for in-hospital mortality are shown in Table 2. The multivariate logistic regression analysis showed that being female $(\mathrm{OR}=5.86,95 \% \mathrm{CI}: 2.03-16.92$, $\mathrm{P}=0.001)$, a Killip class of 2 ( $\mathrm{OR}=8.13,95 \%$ CI: $2.03-$ 32.61, $\mathrm{P}=0.003)$, a Killip class of $4(\mathrm{OR}=17.31,95 \% \mathrm{CI}$ : 3.69-81.27, $\mathrm{P}=0.001)$, a left main coronary artery lesion ( $\mathrm{OR}=44.25,95 \%$ CI: 3.96-494.05, $\mathrm{P}=0.002)$, a final TIMI flow of 1 (OR $=171.83,95 \%$ CI: $28.46-1037.51, \mathrm{P}=0.001)$, a final TIMI flow of 2 (OR =72.93, 95\% CI: 38.54-138.00, $\mathrm{P}=0.001)$, SDT (OR $=1.01,95 \% \mathrm{CI}: 1.00-1.02, \mathrm{P}=0.001)$, SBT $(\mathrm{OR}=1.01,95 \% \mathrm{CI}: 1.00-1.02, \mathrm{P}=0.001)$, and SYNTAX score $(\mathrm{OR}=1.07,95 \% \mathrm{CI}: 1.01-1.12, \mathrm{P}=0.019)$ were risk factors for in-hospital mortality. However, the postoperative application of $\beta$-receptor blockers $(\mathrm{OR}=0.10$, 95\% CI: $0.03-0.30, \mathrm{P}=0.001)$ and ACEI/ARB (OR $=0.13$, 
Table 1 Baseline characteristics

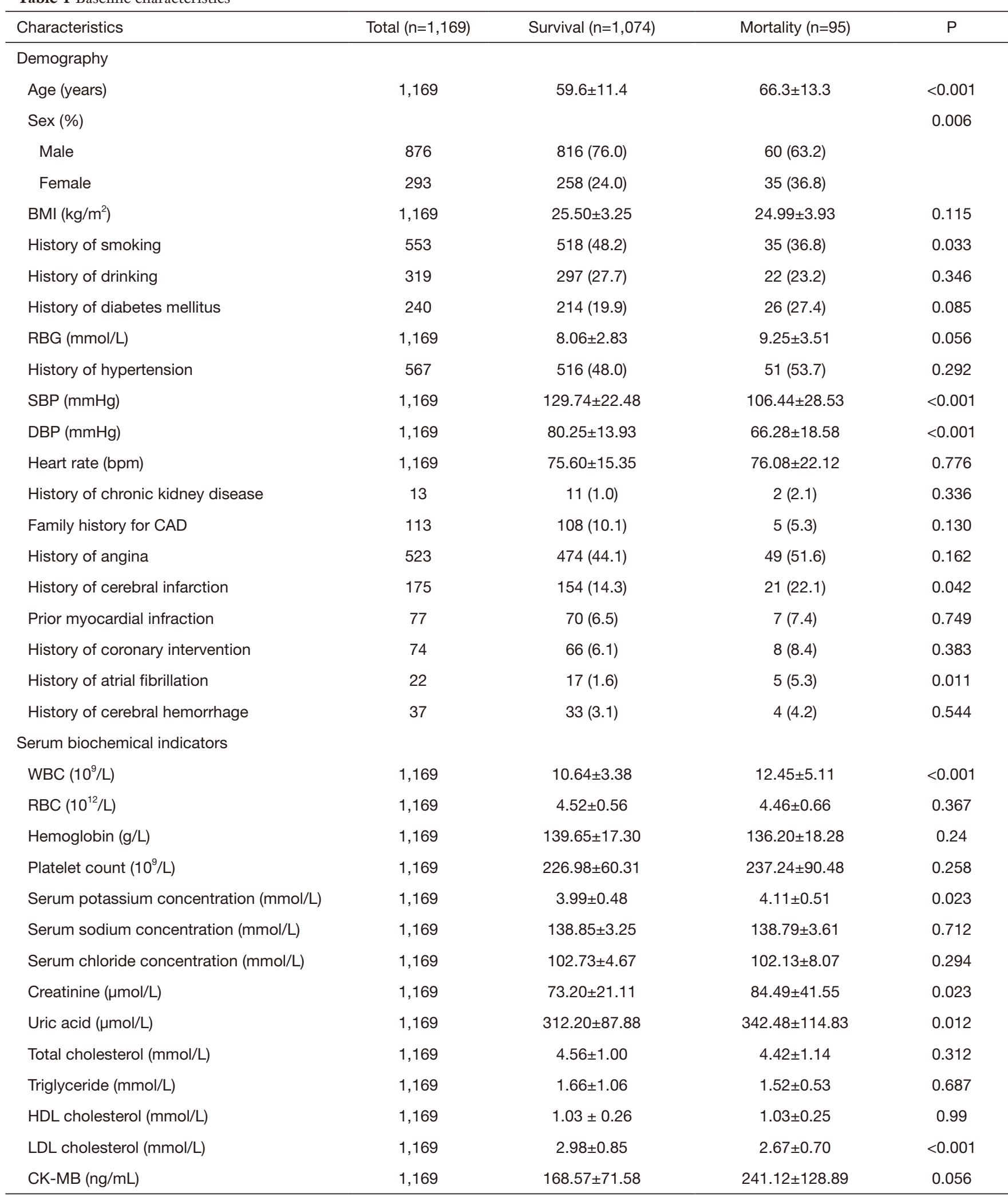

Table 1 (continued) 
Table 1 (continued)

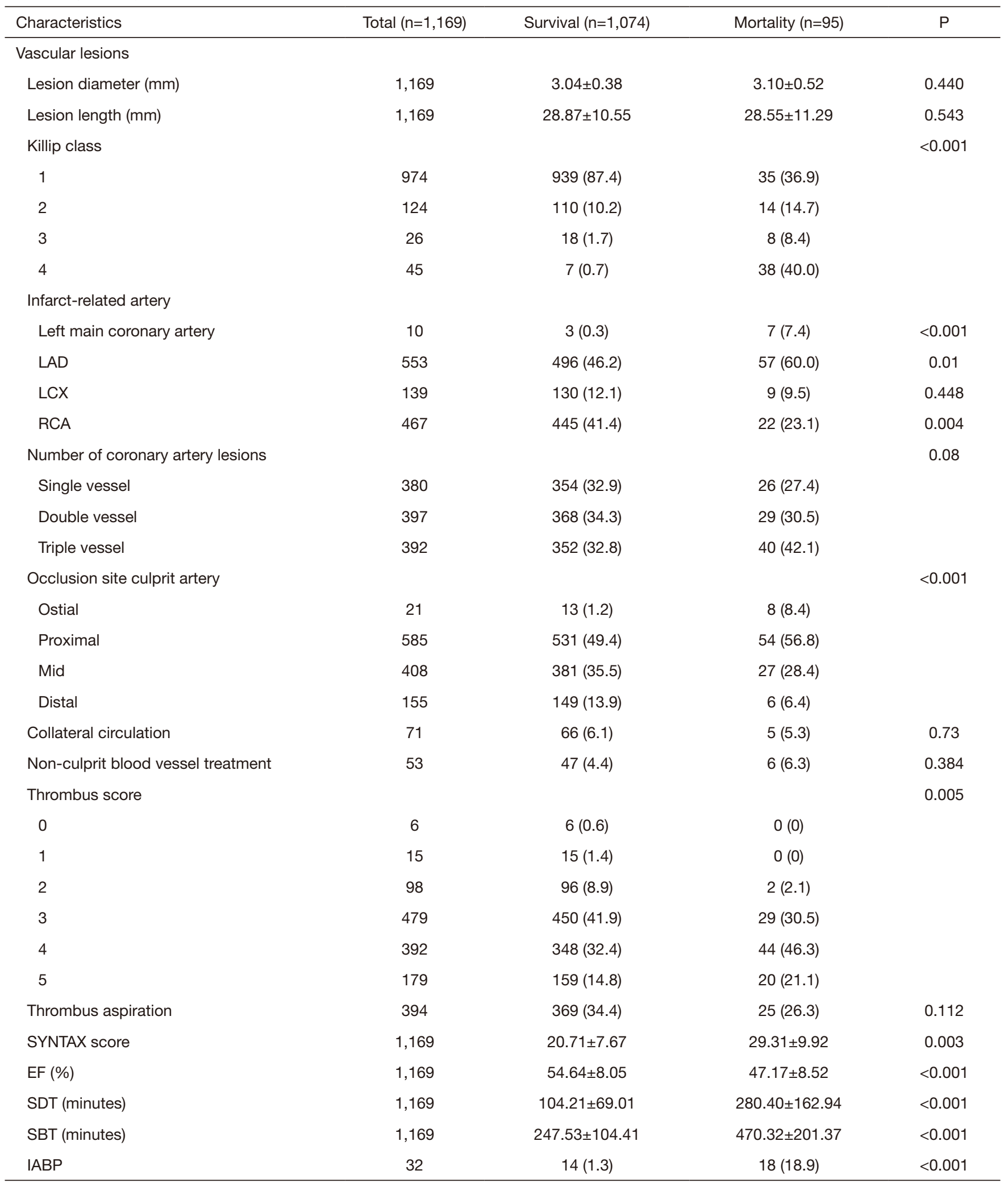

Table 1 (continued) 
Table 1 (continued)

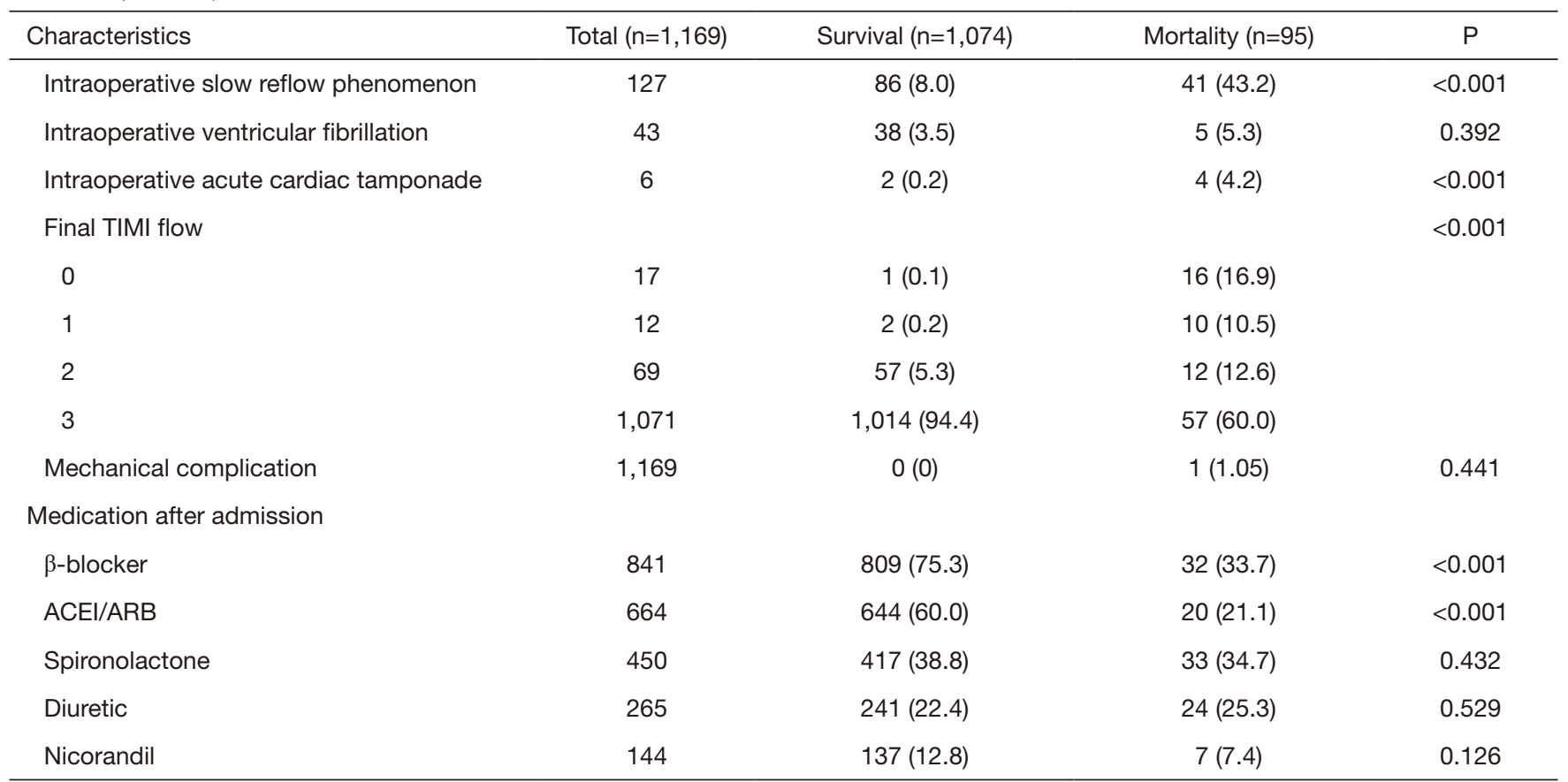

BMI, body mass index; RBG, random plasma glucose; SBP, systolic blood pressure; DBP, diastolic blood pressure; CAD, coronary artery disease; WBC, white blood cell; RBC, red blood cell; HDL, high-density lipoprotein; LDL, low-density lipoprotein; CK-MB, creatine kinaseMB; LAD, left anterior descending artery; LCX, left circumflex artery; RCA, right coronary artery; EF, ejection fraction; SDT, symptom to door time; SBT, symptom to balloon time; IABP, intra-aortic balloon pump; TIMI, thrombolysis in myocardial infarction; ACEI/ARB, angiotensin-converting enzyme/angiotensin receptor blocker.

95\% CI: $0.04-0.44, \mathrm{P}=0.001)$, BMI (OR $=0.85$, 95\% CI: $0.74-0.98, \mathrm{P}=0.024)$, the percentage of ejection fraction (OR $=0.81,95 \%$ CI: $0.75-0.86, \mathrm{P}=0.001)$, and LDL-C (OR $=0.44,95 \%$ CI: $0.21-0.91, \mathrm{P}=0.027)$ were protective factors for in-hospital mortality.

\section{Discussion}

In the research, there were $95(8.13 \%)$ patients died during hospitalization. Of those, 42 patients died of cardiogenic shock, 32 patients died of malignant arrhythmias, 22 patients died of mechanical complications and 8 patients had severe bleeding events.

This study examined the short-term outcomes of a cohort of STEMI patients who underwent PCI to identify risk factors for in-hospital mortality. The results suggest that female gender, a Killip class of 2 or 4, a left main lesion, a TIMI flow of 1 or 2, longer SDT, longer SBT, and a higher SYNTAX score were all risk factors for hospital death after emergency PCI in STEMI patients, while the use of $\beta$-blockers and ACEI/ARB drugs after the procedure, a high
BMI, LVEF, and high LDL-C were protective factors.

Stehli et al. (22) and Lee et al. (17) showed that gender is an independent risk factor for the short- and long-term mortality of patients with AMI. Notably, the risk of death in female patients is significantly higher than in male patients. Thus, analyses of both male and female AMI patients might lead to the omission or inaccuracy of some risk factors. This study examined the 2 genders separately to further identify the factors associated with in-hospital death after emergency PCI in patients with acute ST-elevation myocardial infarction. The results showed that males and females had different risk factors for in-hospital death after emergency PCI for acute ST-elevation myocardial infarction. A factor that increases patient mortality is the no-reflow phenomenon (9-11), and its association with mortality was observed only in females.

With the establishment of chest pain centers, the rate of STEMI patients receiving early PCI has increased significantly, thus reducing the mortality rate. We found that both SDT and SBT were predictors of mortality. However, some registered data from home and abroad show 
Table 2 Analyses of variables associated with in-hospital mortality

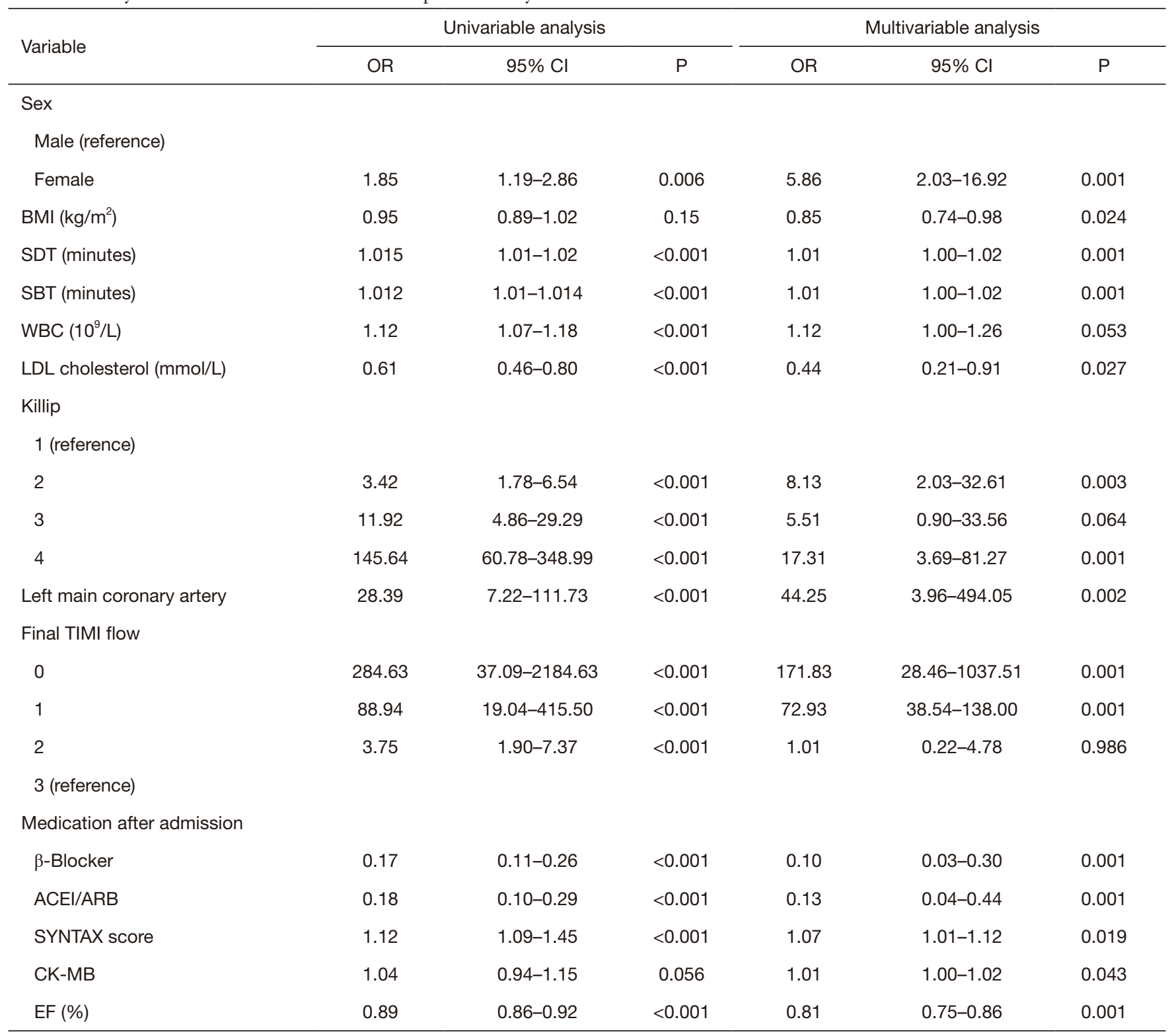

BMI, body mass index; SDT, symptom to door time; SBT, symptom to balloon time; LDL, low-density lipoprotein; CK-MB, creatine kinase$\mathrm{MB}$; EF, ejection fraction; TIMI, thrombolysis in myocardial infarction; ACEI/ARB, angiotensin-converting enzyme/angiotensin receptor blocker.

that STEMI patients still have a high risk of death $(23,24)$. In patients with a symptom duration $>120 \mathrm{~min}$, myocardial perfusion was found to have no significant benefit, and door to balloon time (DBT) in patients with $\mathrm{SBT}>90 \mathrm{~min}$ had little effect on mortality (25). This study found that as the time from onset to first medical contact increased, the risk of death in hospital also gradually increased; the risk of death increased by $1 \%$ for every 1 -minute extension.
Similar to the results of Dudek et al. (26), we found that allcause mortality within 1 year in the SBT group $>3$ hours was higher than that in the SBT group $<3$ hours. Thus, the prolonged opening time of mechanical reperfusion is an important factor affecting the prognosis of STEMI patients. This may be due to the prolongation of total ischemia time, which leads to increased myocardial cell necrosis, decreased viable myocardial cells, and the deterioration of cardiac 
function. It is important to seek medical attention when suspicious symptoms occur so that the onset to first medical contact time can be shortened.

In our study subjects, we also found that the risk of inhospital death in female patients with AMI undergoing emergency PCI was 5.86 times higher than that in male patients. These results are similar to those of previous clinical observation studies, such as those of Tsai et al. (6). In another observational study on gender differences (22), it was also observed that the mortality rate of female patients with AMI within 30 days was significantly higher than that of male patients. Researchers have speculated that this increased risk may be due to atypical chest pain symptoms in female patients, which results in female patients having a significantly longer time from onset to first medical contact than male patients.

Recently, Kim et al. (27) confirmed that even after emergency PCI, 14\% of patients with acute STEMI have left ventricular dysfunction, which is a well-known factor for mortality after AMI. As expected, we found that as LVEF increased, there was a downward trend in the risk of death for in-hospital patients. TIMI and SYNTAX are also well-known factors for mortality $(19,28)$.

In relation to obese patients, the traditional view has always been that obesity is a risk factor for STEMI. However, similar to the results of Kim et al. (29), we found that a high BMI was a protective factor for the risk of in-hospital death among STEMI patients (i.e., the higher the BMI, the lower the risk of in-hospital death among STEMI patients). Another Chinese study found the same results through observations and a study of 35,964 AMI patients. Increased $\mathrm{BMI}$ has been found to be independently related to decreased in-hospital mortality (30). This BMI paradox has also been observed in previous studies (31-33). The present study was not designed to explore the reasons underlying this paradox; however, previous studies have hypothesized that overweight/ obese people have higher metabolic reserves, cachexia is rare in overweight/obese people, overweight/obesity is more common young patients, and high-weight people have larger surface distribution volumes and better drug tolerance for the same dose (31-33). Future studies should seek to examine this paradox more closely.

In this study, high LDL-C was a protective factor, which is counterintuitive given the role of LDL-C levels in the development of AMI (4-7). This LDL-C paradox has been reported in many studies (34-37). Sia et al. (34) reported that high LDL-C was protective in STEMI, while low HDL-C was protective in STEMI. Bambat et al. (35) reported that high LDL-C was protective in patients with acute coronary syndromes. This paradox was observed in a registry study of 115,492 AMI patients (36). Wang et al. (37) speculated that the LDL-C paradox may be mediated by malnutrition; however, nutrition could not be analyzed in the present study. As for the BMI paradox, the present study was not designed to determine the reasons for this paradox; thus, further studies need to be conducted to examine this issue. Although obesity and LDL are risk factors for acute myocardial infarction, once an acute myocardial infarction occurs, it is essential for patients to strengthen nutrition, so as to get them through the critical period.

This study had some limitations. It was a retrospective multicenter study; thus, selectivity bias may have inevitably been included in the results. As the exact cause of death was often unknown, overall survival had to be used instead of cardiac death as the outcome. Further accurate, randomized, and controlled studies may lead to more effective conclusions.

\section{Conclusions}

In conclusion, female gender, Killip grade, a left main lesion, TIMI blood flow grade, time from onset to first medical contact, time from onset to balloon dilatation, and SYNTAX score were associated with a higher risk of hospital death. Conversely, BMI, ejection fraction, LDL-C level, and postoperative use of $\beta$-blocker and ACEI/ARB drugs were associated with a lower in-hospital death risk.

\section{Acknowledgments}

Funding: None.

\section{Footnote}

Reporting Checklist: The authors have completed the STROBE reporting checklist. Available at https://dx.doi. org/10.21037/apm-21-2722

Data Sharing Statement: Available at https://dx.doi. org/10.21037/apm-21-2722

Conflicts of Interest: Both authors have completed the ICMJE uniform disclosure form (available at https://dx.doi. org/10.21037/apm-21-2722). The authors have no conflicts of interest to declare.

Ethical Statement: The authors are accountable for all 
aspects of the work in ensuring that questions related to the accuracy or integrity of any part of the work are appropriately investigated and resolved. All procedures performed in this study involving human participants were in accordance with the Declaration of Helsinki (as revised in 2013). The study was approved by institutional ethics research committee board of Baoding No. 1 Central Hospital (No. [2021]014). Individual consent for this retrospective analysis was waived.

Open Access Statement: This is an Open Access article distributed in accordance with the Creative Commons Attribution-NonCommercial-NoDerivs 4.0 International License (CC BY-NC-ND 4.0), which permits the noncommercial replication and distribution of the article with the strict proviso that no changes or edits are made and the original work is properly cited (including links to both the formal publication through the relevant DOI and the license). See: https://creativecommons.org/licenses/by-nc-nd/4.0/.

\section{References}

1. Murray CJ, Lopez AD. Global mortality, disability, and the contribution of risk factors: Global Burden of Disease Study. Lancet 1997;349:1436-42.

2. Chen JS, Ko WJ, Yu HY, et al. Analysis of the outcome for patients experiencing myocardial infarction and cardiopulmonary resuscitation refractory to conventional therapies necessitating extracorporeal life support rescue. Crit Care Med 2006;34:950-7.

3. Benjamin EJ, Virani SS, Callaway CW, et al. Heart Disease and Stroke Statistics-2018 Update: A Report From the American Heart Association. Circulation 2018;137:e67-e492.

4. Santoro GM, Carrabba N, Migliorini A, et al. Acute heart failure in patients with acute myocardial infarction treated with primary percutaneous coronary intervention. Eur J Heart Fail 2008;10:780-5.

5. DeGeare VS, Boura JA, Grines LL, et al. Predictive value of the Killip classification in patients undergoing primary percutaneous coronary intervention for acute myocardial infarction. Am J Cardiol 2001;87:1035-8.

6. Tsai TH, Chua S, Hussein H, et al. Outcomes of patients with Killip class III acute myocardial infarction after primary percutaneous coronary intervention. Crit Care Med 2011;39:436-42.

7. Shiraishi J, Kohno Y, Nakamura T, et al. Predictors of inhospital outcomes after primary percutaneous coronary intervention for acute myocardial infarction in patients with a high Killip class. Intern Med 2014;53:933-9.

8. Sen S, Davies JE, Malik IS, et al. Why does primary angioplasty not work in registries? Quantifying the susceptibility of real-world comparative effectiveness data to allocation bias. Circ Cardiovasc Qual Outcomes 2012;5:759-66.

9. Tasar O, Karabay AK, Oduncu V, et al. Predictors and outcomes of no-reflow phenomenon in patients with acute ST-segment elevation myocardial infarction undergoing primary percutaneous coronary intervention. Coron Artery Dis 2019;30:270-6.

10. Fajar JK, Heriansyah T, Rohman MS. The predictors of no reflow phenomenon after percutaneous coronary intervention in patients with ST elevation myocardial infarction: A meta-analysis. Indian Heart J 2018;70 Suppl 3:S406-18.

11. Celik T, Balta S, Ozturk C, et al. Predictors of NoReflow Phenomenon in Young Patients With Acute STSegment Elevation Myocardial Infarction Undergoing Primary Percutaneous Coronary Intervention. Angiology 2016;67:683-9.

12. Solano-López J, Zamorano JL, Pardo Sanz A, et al. Risk factors for in-hospital mortality in patients with acute myocardial infarction during the COVID-19 outbreak. Rev Esp Cardiol (Engl Ed). 2020;73:985-993.

13. Ibanez B, James S, Agewall S, et al. 2017 ESC Guidelines for the management of acute myocardial infarction in patients presenting with ST-segment elevation: The Task Force for the management of acute myocardial infarction in patients presenting with ST-segment elevation of the European Society of Cardiology (ESC). Eur Heart J 2018;39:119-77.

14. O'Gara PT, Kushner FG, Ascheim DD, et al. 2013 ACCF/ AHA guideline for the management of ST-elevation myocardial infarction: a report of the American College of Cardiology Foundation/American Heart Association Task Force on Practice Guidelines. J Am Coll Cardiol 2013;61:e78-e140.

15. Li P, Ruan JW, Liu M, et al. Thrombus aspiration catheter improve the myocardial reperfusion of STEMI patients with high thrombus load during the emergency PCI operation. J Cardiothorac Surg 2019;14:172.

16. Killip T 3rd, Kimball JT. Treatment of myocardial infarction in a coronary care unit. A two year experience with 250 patients. Am J Cardiol 1967;20:457-64.

17. Lee M, Kim DW, Park MW, et al. Gender differences in clinical outcomes of acute myocardial infarction 
undergoing percutaneous coronary intervention: insights from the KAMIR-NIH Registry. J Geriatr Cardiol 2020;17:680-93.

18. Lang RM, Badano LP, Mor-Avi V, et al. Recommendations for cardiac chamber quantification by echocardiography in adults: an update from the American Society of Echocardiography and the European Association of Cardiovascular Imaging. J Am Soc Echocardiogr 2015;28:1-39.e14.

19. Bundhun PK, Sookharee Y, Bholee A, et al. Application of the SYNTAX score in interventional cardiology: A systematic review and meta-analysis. Medicine (Baltimore) 2017;96:e7410.

20. Burzotta F, Trani C, Romagnoli E, et al. A pilot study with a new, rapid-exchange, thrombus-aspirating device in patients with thrombus-containing lesions: the Diver C.E. study. Catheter Cardiovasc Interv 2006;67:887-93.

21. TIMI Study Group. The Thrombolysis in Myocardial Infarction (TIMI) trial. Phase I findings. N Engl J Med 1985;312:932-6.

22. Stehli J, Martin C, Brennan A, et al. Sex Differences Persist in Time to Presentation, Revascularization, and Mortality in Myocardial Infarction Treated With Percutaneous Coronary Intervention. J Am Heart Assoc 2019;8:e012161.

23. Doost Hosseiny A, Moloi S, Chandrasekhar J, et al. Mortality pattern and cause of death in a long-term follow-up of patients with STEMI treated with primary PCI. Open Heart 2016;3:e000405.

24. Ward MJ, Kripalani S, Zhu Y, et al. Incidence of emergency department visits for ST-elevation myocardial infarction in a recent six-year period in the United States. Am J Cardiol 2015;115:167-70.

25. Brodie BR, Gersh BJ, Stuckey T, et al. When is door-toballoon time critical? Analysis from the HORIZONSAMI (Harmonizing Outcomes with Revascularization and Stents in Acute Myocardial Infarction) and CADILLAC (Controlled Abciximab and Device Investigation to Lower Late Angioplasty Complications) trials. J Am Coll Cardiol 2010;56:407-13.

26. Dudek D, Brener SJ, Rakowski T, et al. Efficacy of an Embolic Protection Stent as a Function of Delay to Reperfusion in ST-Segment Elevation Myocardial Infarction (from the MASTER Trial). Am J Cardiol 2014;114:1485-9.

27. Kim DH, Park CB, Jin ES, et al. Predictors of decreased left ventricular function subsequent to follow-up echocardiography after percutaneous coronary intervention following acute ST-elevation myocardial infarction. Exp Ther Med 2018;15:4089-96.

28. Sarak T, Karadeniz M. The relationship between serum NT-proBNP levels and severity of coronary artery disease assessed by SYNTAX score in patients with acute myocardial infarction Turk J Med Sci 2019;49:1366-73.

29. Kim DW, Her SH, Park HW, et al. Association between body mass index and 1-year outcome after acute myocardial infarction. PLoS One 2019;14:e0217525.

30. Song C, Fu R, Yang J, et al. The association between body mass index and in-hospital outcome among patients with acute myocardial infarction-Insights from China Acute Myocardial Infarction (CAMI) registry. Nutr Metab Cardiovasc Dis 2019;29:808-14.

31. Neeland IJ, Das SR, Simon DN, et al. The obesity paradox, extreme obesity, and long-term outcomes in older adults with ST-segment elevation myocardial infarction: results from the NCDR. Eur Heart J Qual Care Clin Outcomes 2017;3:183-91.

32. Witassek F, Schwenkglenks M, Erne P, et al. Impact of Body Mass Index on mortality in Swiss hospital patients with ST-elevation myocardial infarction: does an obesity paradox exist? Swiss Med Wkly 2014;144:w13986.

33. Bucholz EM, Rathore SS, Reid KJ, et al. Body mass index and mortality in acute myocardial infarction patients. Am J Med 2012;125:796-803.

34. Sia CH, Zheng H, Ho AF, et al. The Lipid Paradox is present in ST-elevation but not in non-ST-elevation myocardial infarction patients: Insights from the Singapore Myocardial Infarction Registry. Sci Rep 2020;10:6799.

35. Bambat $O$, Udayachalerm $W$, Buddhari $W$, et al. LDL Cholesterol and 1-Year Mortality Rate after Acute STElevation Myocardial Infarction. J Med Assoc Thai 2018;101:731-7.

36. Reddy VS, Bui QT, Jacobs JR, et al. Relationship between serum low-density lipoprotein cholesterol and in-hospital mortality following acute myocardial infarction (the lipid paradox). Am J Cardiol 2015;115:557-62.

37. Wang B, Liu J, Chen S, et al. Malnutrition affects cholesterol paradox in coronary artery disease: a 41,229 Chinese cohort study. Lipids Health Dis 2021;20:36.

Cite this article as: Gao N, Qi XY. Risk factors for in-hospital death in acute ST-segment elevation myocardial infarction after emergency percutaneous coronary intervention: a multicenter retrospective study. Ann Palliat Med 2021;10(11):11756-11766. doi: 10.21037/apm-21-2722 